\title{
BEHAVIOR ON PLASTIC DEFORMATION OF THIN STEEL STRIPS COATED WITH ELECTROLESS Ni-P
}

\author{
Tamara RADU, Florentina POTECASU \\ "Dunarea de Jos" University of Galati, Romania \\ e-mail: tradu@ugal.ro
}

\begin{abstract}
Within the present work deformability of Ni-P coatings was analyzed on thin strips of low carbon steel, coated with $\mathrm{Ni}$-P layers in correlation with their structure and chemical composition. Thin layers of 2-7 $\mu \mathrm{m}$ were made at immersion times of 5, 10 and 15 minutes and a variable $p H$ of between 4 and 6, at a temperature of $80-85^{\circ} \mathrm{C}$. The deformability was analyzed by applying the Erichsen Test, which measures the deep deformation capacity of the metallic materials. Following the analysis was established the Erichsen Index (IE) the most used index for assessing the deformation capacity of the sheets.

The microscopic analysis, performed on the surface of maximum deformation, shows a cracking of the layers with a different aspect depending on $\mathrm{pH}$, the duration of deposition and the initial structure of the layer. The results of the Errichsen test show a good behavior at plastic deformation of the strips covered with thin Ni-P layers.
\end{abstract}

KEYWORDS: layers, Ni-P, electroless, microstructure, Erichsen Index

\section{Introduction}

Ni-P layers on steel support are obtained by electroless method which consists in immersing the support in a solution containing a nickel salt and a reducer, respectively sodium hypophosphite [1, 2]. The chemical coating process of nickel was first observed in 1844 by Wurtz One hundred years later, in 1946, Brenner and Riddell began experiments to develop such a process that could be applied in practice [2].

The study of the Ni deposition process by this method continued to be of interest and the research carried out led to the development of the process that the inventors initially called electrodeless, then electroless [3].

Compared to the electrolytic coatings, the deposits obtained by the chemical method are usually less porous and more resistant to corrosion (at equal thicknesses) [4, 5]. Almost any surface can be covered: metallic or non-metallic, including polymers (plastics), ceramics. The performances of this type of coverage have led to their use in various industrial fields: cellulose and paper production, plastics, food, petroleum-petrochemical, textile, automotive, aeronautical, electronic, nuclear industry $[6,7]$.
Deposits obtained by the chemical method are mainly used in applications that require significantly improved characteristics for the deposited layer, the most important being uniformity of thickness, hardness, high resistance to wear and corrosion [8].

These applications may require plastic deformations of the products and it is important to analyze this behavior. In the present work the deformability was analyzed by applying the Erichsen Test, which measures the deep deformation capacity of the metallic materials. Following the analysis was established the Erichsen Index (IE), the most used index for assessing the deformation capacity of the sheets steel, in this case coated with Ni-P layers.

\section{Experimental conditions}

Ni-P layers were deposited on a thin steel strip $(0.18 \mathrm{~mm})$ with low carbon content $(0.025 \%)$. Samples were cleaned by chemical degreasing in alkalis at $90{ }^{\circ} \mathrm{C}$, pickled in $15 \% \mathrm{HCl}$ solution and two washes in distilled water at $90{ }^{\circ} \mathrm{C}$. The composition of the baths for Ni-P coatings obtaining are shown in Table 1.

Sodium acetate was added as a complexing agent and as a buffer solution and lead acetate was used as a stabilizer [9].

The working parameters are shown in Table 2. 
Table 1. Composition of the baths

\begin{tabular}{cc} 
Bath components & [g/L] \\
\hline Nickel Sulphate & $20-26$ \\
Sodium Hypophosphite & $19-23$ \\
Sodium Acetate & $9-15$ \\
Lead Acetate & $1-3$
\end{tabular}

Table 2. The working parameters

\begin{tabular}{|c|c|c|c|}
\hline $\mathbf{p H}$ & ${\mathbf{T ~}\left[{ }^{\mathbf{}} \mathbf{C}\right]}$ & Time [min] & Stirring rate [rot/min] \\
\hline $4.0-6.0$ & $80-85$ & $5,10,15$ & $300-600$ \\
\hline
\end{tabular}

The coating was performed on a laboratory plant consisting in a coating bath, with volume $1 \mathrm{~L}$, thermostated hob and magnetic stirrer, $\mathrm{pH}$ meter and thermometer.

\section{Experimental results and discussions}

\subsection{Microstructure and layer thickness}

The analysis by optical microscopy of the Ni-P layers, in the cross-section shows that in the case of the thin layers, there is a faithful tracking of the contour of the surface of the steel support (Fig. 1a) and at the increase of the thickness of the layer the roughness fades (Fig. 1b) and the layers become uniform (Fig. 1c) [10]. It is also observed that the Ni$\mathrm{P}$ layer adheres perfectly to the steel substrate, the interface being without discontinuities.

The thickness of the layer is influenced by $\mathrm{pH}$. As $\mathrm{pH}$ increases, the thickness of the layer increases due to the increase of the nickel reduction reaction rate. Lowering the $\mathrm{pH}$, below 4 , leads to a significant decrease of the layer thickness, the deposition process becoming very slow [11]. In addition to the $\mathrm{pH}$, the sample exposure time in the electroless bath significantly influences the layer thickness. As can be seen in Figure 1, the layer thickness at $\mathrm{pH} 4.95$ and at a working temperature $83{ }^{\circ} \mathrm{C}$ is doubled when increasing the immersion time from 5 (Fig. 1a) to 15 (Fig. 1c) minutes. Research has shown that the layer thickness can be also increased by applying a higher stirring speed or introducing completely dry samples into the electroless bath. These influences have not been verified yet on a sufficient number of samples allowing safety outcomes. High stirring speed provides better removal of the hydrogen formed around the sample preventing $\mathrm{pH}$ decrease during the process [12]. Clean and dry samples may have an activation energy higher than in the presence of a water film on the surface, thus facilitating the deposition process.

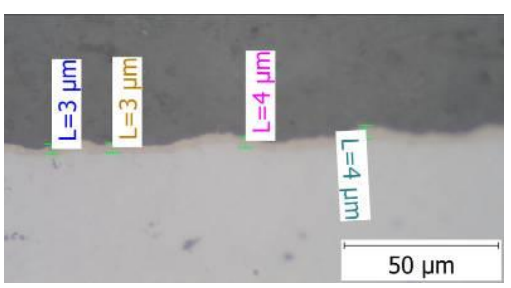

a) $5 \mathrm{~min}$

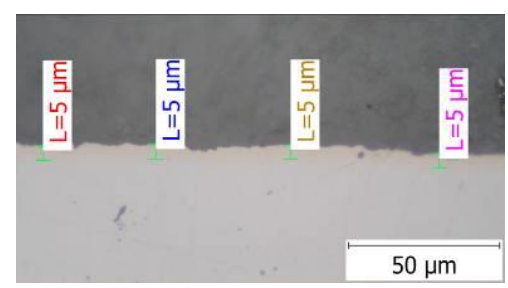

b)10 min.

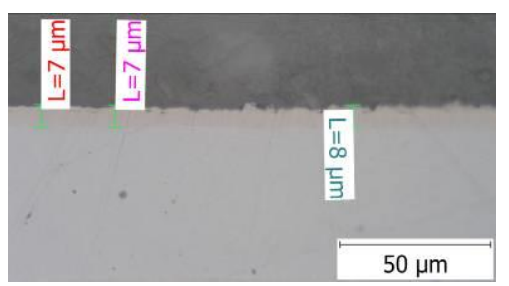

c) $15 \mathrm{~min}$

Fig. 1. The influence of immersion time on layer thickness, $p H=4.95,83{ }^{\circ} \mathrm{C}$

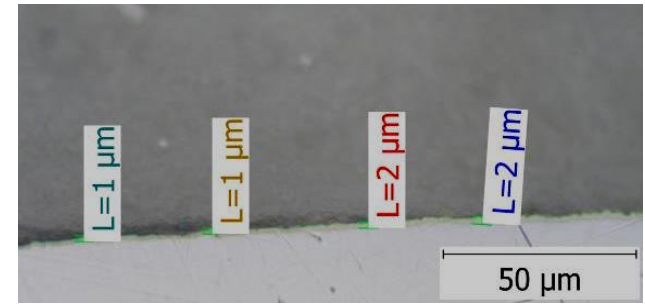

a) $80^{\circ} \mathrm{C}$

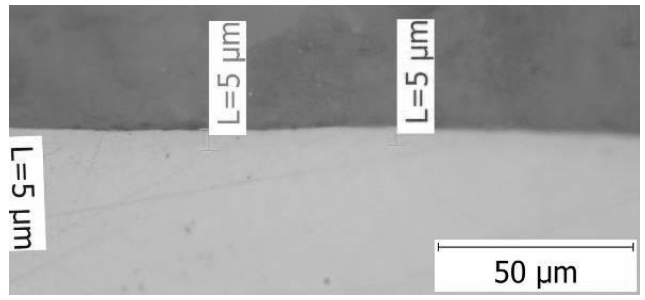

b) $84{ }^{\circ} \mathrm{C}$

Fig. 2. The influence of electroless bath temperature on layer thickness 
As is known from the literature, increasing the electroless bath temperature favors the deposition process. Figure 2 shows that an increase in temperature by $5{ }^{\circ} \mathrm{C}$ can provide an increase up to 3-4 $\mu \mathrm{m}$ of the layer thickness at the same $\mathrm{pH}$ and work duration. Electroless method does not allow, however, a working temperature higher than $90{ }^{\circ} \mathrm{C}$ with the risk of destabilizing the bath [2].

\subsection{Testing Adhesion and Plasticity by Erichsen Method}

Erichsen test measures the capacity of deep deformation of metallic materials or deformability. The test consists of deformation by a punch with a hemispherical head up of a sample until it breaks in order to determine the maximum of the depth of the indentation left by the penetrator. The penetration depth in millimeters is the Erichsen Index (IE), the most widely used index for assessing the capacity of steel strips deformation $[13,14]$.

At steel strips coated with metals this test can give indications on deformation capacity of that product (steel strips coated with a layer) and on the layer adherence to the steel support. The test on thin steel strips of $0.18 \mathrm{~mm}$, coated with Ni-P, obtained in different conditions of nickel plating, was carried out on a test device by using a ball $\varphi=15 \mathrm{~mm}$. Erichsen index was rated as the average of three measurements. Table 3 shows the values obtained for the samples tested depending on the obtaining conditions.

Table 3. Erichsen index depending on nickel plating parameters

\begin{tabular}{|c|c|c|c|}
\hline Sample code* & $\mathbf{p H}^{* *}$ & $\begin{array}{c}\mathbf{t}^{* * * *} \\
{[\mathbf{m i n}]}\end{array}$ & IE median \\
\hline E1 & 6.6 & 5 & 6.67 \\
\hline E2 & 6.6 & 5 & 6.70 \\
\hline E3 & 5.11 & 5 & 6.61 \\
\hline E4 & 5.11 & 15 & 6.19 \\
\hline E5 & 4.32 & 15 & 6.41 \\
\hline E6 & 4.32 & 15 & 6.50 \\
\hline
\end{tabular}

* There was a special nickel-plating for the samples dimensionally corresponding to the test

** The bath $\mathrm{pH}$ dropped freely as a result of successive coating of the samples

*** Immersion time

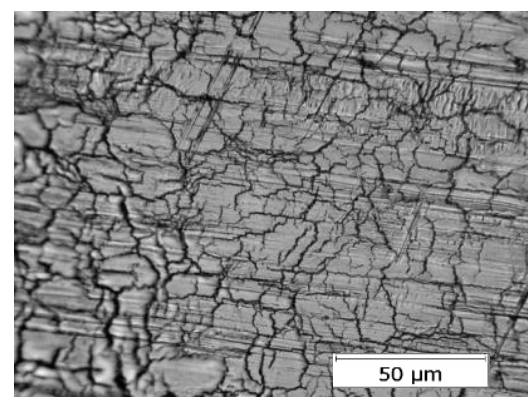

E1

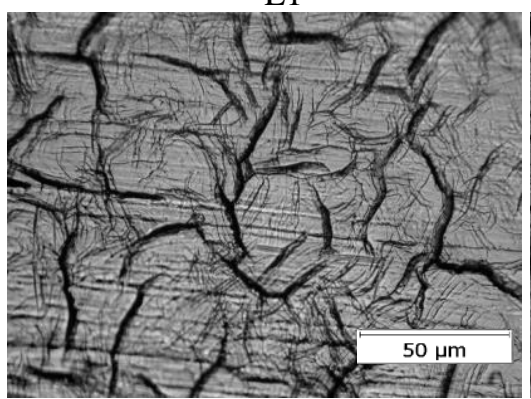

E4

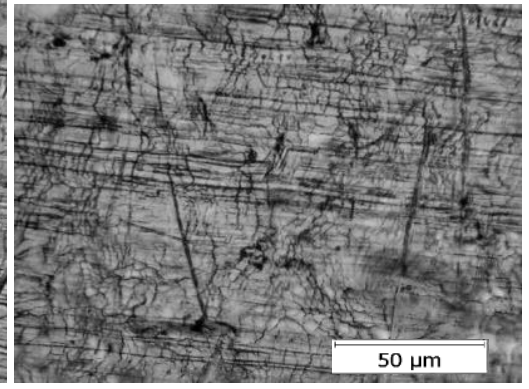

E2

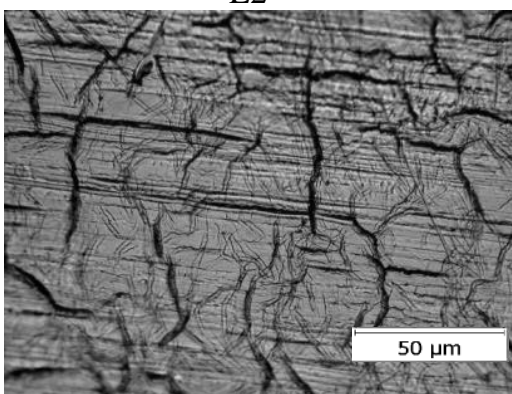

E5

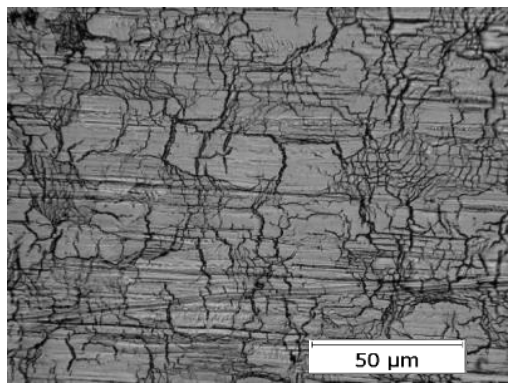

E3

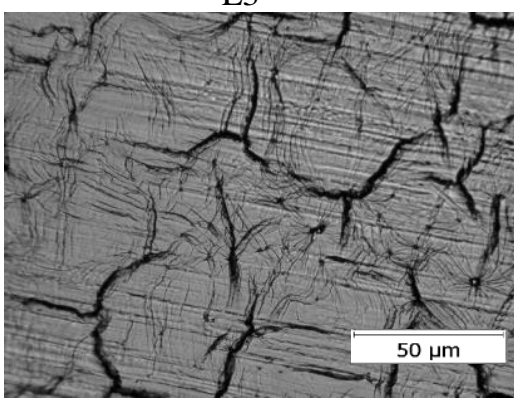

E6

Fig. 3. The appearance of the surface on maximum deformation area of the Erichsen tested samples 
The microscopic analysis, performed on the area of maximum deformation, reveals a cracking of layers of different appearance depending on the $\mathrm{pH}$ and duration of deposit, as presented in Figure 3. It can be noted that samples made at high $\mathrm{pH}$ and duration of 5 minutes (code E1, E2, E3) due to a finer structure, also visible from the surface morphology analysis, shows a fine network of cracks. The samples obtained at 15 minutes immersion time and medium and low and average $\mathrm{pH}$ (code E4, E5, E6), which revealed microscopically a bigger granulation, showed a coarse network of cracks. The same difference is observed in function of the immersion time as seen at E3 and E4 samples obtained at the same pH. All samples, regardless deposition conditions, present numerous slip lines.

Macroscopic analysis of Erichsen tested samples does not reveal exfoliated layer, cap surface is smooth, just like the cracked area, as shown in Figure 4. This result shows a very good adhesion of Ni-P layers to steel support which is also highlighted by microscopic analysis in cross section showing a layer - steel interface free of discontinuities.

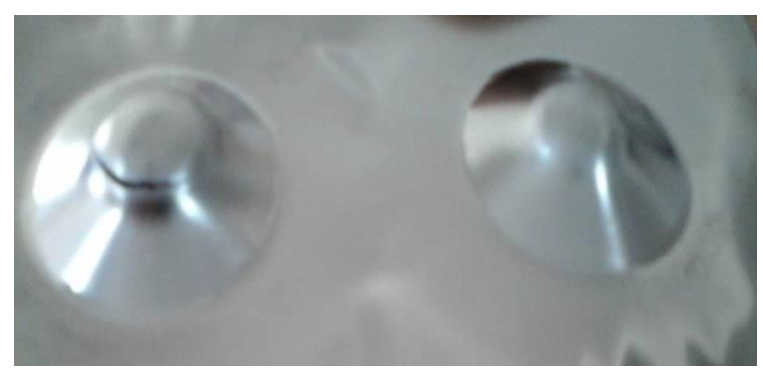

Fig. 4. Macroscopic aspect of Erichsen deformation

Erichsen test results show a close behavior to the plastic deformation of thin strips coated with Ni-P thin layers. Small variations can be correlated with greater thickness of layers obtained at deposition times of $15 \mathrm{~min}$. vs those obtained at $5 \mathrm{~min}$.

\section{Conclusions}

- Thin films of 2-7 $\mu \mathrm{m}$ Ni-P deposited, by electroless method, on cold rolled thin strip were obtained.

- Microstructural analysis reveals uniform layers in a continuous and clean interface with the support band.

- Macroscopic analysis of samples subjected to Erichsen test does not reveal exfoliated layer, cap surface is smooth just like the fissured area. This result shows a very good adhesion of layers Ni-P to the steel support.

- Microscopic analysis performed on the area of maximum deformation of the Erichsen samples show that samples made in 5 minutes shows a fine network of cracks and samples obtained at 15 minutes immersion time show a coarse network including numerous slip lines. Erichsen index value shows a similar behavior to plastic deformation of strips coated with Ni-P thin layers.

\section{References}

[1]. Schlesinger M., Electroless Deposition of Nickel, Modern Electroplating, (Book) Fifth Edition Edited by Mordechay Schlesinger and Milan Paunovic, 2010.

[2]. Krishnan K. H., John S., Srinivasan K. N., Praveen J., Ganesan M., Kavimani P. M., An Overall Aspect of Electroless Ni-P Depositions-A Review Article, Metallurgical and Materials Transactions A, vol. 37A, p. 1917-1925, June 2006.

[3]. Taheri R., Evaluation of Electroless Nickel-Phosphorus (EN) Coatings, Spring 2003, Copyright R. Taheri, p. 40-45, 2002.

[4]. Weil R., Parker K., The Properties of Electroless Nickel, William Andrew Publishing/Noyes from www.Knovel.com, Copyring 1990.

[5]. Gina Genoveva Istrate, Tamara Radu, Corrosion Behavior of Ni-P Coated Steel Strips, The Annals of "Dunarea de Jos" University of Galati. Fascicle IX. Metallurgy and Materials Science, no. 3, p. 48-52, 2015.

[6]. Mallory G. O., Hajdu J. B., Electroless Plating: Fundamentals and Applications, Cambridge University Press, Cambridge, 1990.

[7]. Tamara Radu, Obtaining of the Ni-P coatings on steel strips, Advanced Materials Research, vol. 1143, p. 20-25, 2017.

[8]. Mainier B. F., et al., Quality of Electroless Ni-P (NickelPhosphorus) Coatings Applied in Oil Production Equipment with Salinity, Journal of Materials Science and Chemical Engineering, 1, p. 1-8, 2013.

[9]. Tamara Radu, Ni-P coating on steel support by electroless method, The Annals of "Dunarea de Jos" University of Galati. fascicle IX. Metallurgy and Materials Science, 2017.

[10]. Florentina Potecasu, Tamara Radu, The Influence of the Steel's Surface Quality on the Electroless Ni-P Coatings, The Annals of "Dunarea de Jos" University of Galati. Fascicle IX. Metallurgy and Materials Science, no. 1, p. 49-53, 2015.

[11]. Istrate G. G., Balint S. I., Ciocan A., Dragan V., Influence of technological parameters on layer thickness to obtain $\mathrm{Ni}-\mathrm{P}$ electroless coatings, $15^{\text {th }}$ International Multidisciplinary Scientific GeoConference SGEM 2015, Book 6, vol. 1, p. 113-125, 2015.

[12]. Sevugan K., Selvam M., et al., Effect of Agitation in Electroless Nickel Deposition, Plating and Surface Finishing, p. 56$58,1993$.

[13]. Akrout M., Ben Amar M., Chaker C., Dammak F., Numerical and experimental study on the Erichsen test for metal stamping, Advances in Production Engineering \&Management, 3(2008) 2, p. 81-92.

[14]. Talapatra A., Agarwal S. K., Saha J., Formability characterisation of composite sheet materials by Erichsen cupping testing method, Materials Science, 2014. 